\title{
Design Students' Theories of Creativity: A Macau Perspective
}

\author{
Kuan Chen Tsai (Corresponding author) \\ Faculty of Humanities and Social Sciences, City University of Macau \\ Avenida Padre Tomás Pereira Taipa, Macau \\ Tel: 853-8590-2733Ｅ-mail: tsaikuanchen@cityu.edu.mo
}

Received: January 28, 2016 Accepted: February 11, 2016 Published: February 23, 2016

doi:10.5296/jad.v2i1.8949 URL: http://dx.doi.org/10.5296/jad.v2i1.8949

\begin{abstract}
Explicit theories are constructed by experts based on the findings of empirical studies. Implicit theories, on the other hand, are generated from assumptions and ideas held by non-experts. The purpose of the current study was to examine Chinese art and design undergraduates' perceptions of creativity. The implicit theories of this concept that are held by art and design students are perhaps disproportionately important, in that they might inform creative work in the real world. The current study was a qualitative survey and utilized convenience sampling to recruit 95 participants, all third-year college students in art and design in Macau. The current study was a qualitative survey, distributed online, and consisting of demographic questions and a single open-ended question: "When you hear the word 'creativity', what words come into your mind? We found that the majority of the most popular responses seemed to reflect the creativity literature, with new, unique, surprise, and interesting. In addition, among these four attributes, female students were significantly more concerned that creativity should have new and interesting components than their male counterparts did.
\end{abstract}

Keywords: Implicit theories of creativity, Qualitative survey, Art and design Chinese undergraduates, Macau

\section{Introduction}

Explicit theories are constructed by experts based on the findings of empirical studies (Sternberg, 1985). Implicit theories, on the other hand, are generated from assumptions and ideas held by non-experts (Paletz, Peng, \& Li, 2011). In defining creativity, psychologists have often argued that creativity should include two elements, novelty and usefulness (see 
Hennessey \& Amabile, 2010), but it is likely that non-psychologist would define the concept differently; this in turn reflects differences in how the two groups - i.e., experts and non-experts - assess creative works (Lan \& Kaufman, 2012). Although explicit theories and implicit theories of the same construct are often quite different, it has been proposed that implicit theories can be a useful cornerstone for developing explicit theories of creativity (Sternberg, 1985). As such, it is important to investigate the implicit theories of creativity that prevail among ordinary people. Studies of culture-specific implicit creativity, meanwhile, can help us go beyond limited views of creativity and greatly enrich the creativity literature (Misra, Srivastava, \& Misra, 2006).

Accordingly, the purpose of the current study was to examine Chinese art and design undergraduates' perceptions of creativity. The implicit theories of this concept that are held by art and design students are perhaps disproportionately important, in that they might inform creative work in the real world; and studying them may help art educators to foster creativity among these students. Guided by the main objective of this study, we asked two research questions: (a) How do Chinese art and design students in Macau perceive creativity? and (b) Does gender affect these perceptions?

\section{Literature Review}

Four cross-cultural studies of implicit theories of creativity have been conducted since 2000, and are reviewed in this section. The most recent, by Ramos and Puccio (2014), compared the influence of culture on implicit theories of creativity in the United States and Singapore, using the innovative-adaptive style of creativity from Kirton's (1976) creativity framework. The results indicated that non-experts from both countries believed high levels of creativity to be more prevalent among innovators. Indeed, both national samples seemed to reveal what might be called an innovator bias in their implicit theories of creativity, with frequent use of words and phrases such as think out of the box, new, unusual, and different. However, the concept of usefulness was notably absent from the implicit theories held by participants of both nationalities.

Runco and Johnson (2002) investigated parents' and teachers' implicit theories of creativity in children, using social-validation methods across two cultures (India and the U.S.). The researchers employed a single instrument to ask parents and teachers to rate a series of adjectives connected to creativity and desirability thereof. The results showed that Indian and U.S. parents and teachers viewed traits commonly considered to be creative or uncreative in very similar ways: i.e., favorably in the case of creative traits, and unfavorably in the case of uncreative ones. While the study's findings suggested that parents' and teachers' ideas were not qualitatively different, parents and teachers in the U.S. endorsed certain aspects of creativity significantly more strongly than either group in India did.

Paletz and Peng (2008) surveyed students from Japan, China, and the U.S. about their reactions to two products - a textbook for a college course and a meal cooked by a friend in terms of their novelty and appropriateness. The results suggested that creativity might be consistent across cultures, at least in certain ways. The participants from all three countries rated novelty as very important, whereas appropriateness was more important for Americans 
and Japanese than for Chinese when assessing product creativity. In general, both novelty and appropriateness had strong effects on the participants' ratings of both creativity and desirability, but novelty was more important to ratings of the former, and appropriateness more important to ratings of the latter.

Lastly, Paletz et al. (2011) studied the implicit theories of creativity held by Japanese, Chinese, Caucasian-American, and Asian-American undergraduates. Their participants were asked to write down activities and traits they associated with creative individuals and groups. The results revealed that, as compared to the Caucasian-Americans, the Japanese were more likely to mention visible and interactive types of activities and traits (e.g., sports and cooperativeness), and less likely to mention internal activities and traits (e.g., thinking and intelligence). In addition, when the researchers controlled for age and major, the odds of Americans - and particularly Caucasians - choosing internal' professions such as architecture as creative were greater than those of Asian nationals. These findings suggested that ideas about creativity were more influenced by modern cultural learning than by the transmission of ancient traditions; and that some combination of training bias and gender socialization might influence people's perceptions of creativity. Taken as a whole, then, the findings of prior cross-cultural studies of implicit theories of creativity support the idea that such theories are influenced by cultural traditions and expectations.

\section{Methods}

\subsection{Participants}

The current study utilized convenience sampling to recruit 95 participants, all third-year college students in art and design in Macau, ranging from 20 to 24 years of age $(M=20.72$; $S D=.99)$. There were 35 males in the sample and 60 females. The data were collected during the last week of each semester in the 2014-2015 academic year.

\subsection{Measures and Procedures}

The current study was a qualitative survey, distributed online, and consisting of demographic questions and a single open-ended question: "When you hear the word 'creativity', what words come into your mind? Please list those words you associate with creativity below." It took 10 minutes to complete. The respondents received extra credit in return for their participations.

\subsection{Coding}

The entire list of participant-generated words and phrases were coded using HyerRESEARCH 3.5 (2013) software. The final coding scheme contains six broad categories: trait terms (e.g., new and unique), internal activities (e.g., imagination and expression), external activities (e.g., painting and music), products (e.g., mobile phone), career types (e.g., artists and musicians), and miscellaneous (e.g., future and life). The average participant listed five words. 


\section{Macrothink}

\section{Results}

Table 1 shows the top 12 from among a total of 95 different codes, which taken together account for 167 or $47.5 \%$ of a total of 351 responses received; the same codes also represent the relative importance of the attributes of creativity, as seen by our sample. The top two categories nominated by our Macau sample were new, which accounted for $5.9 \%$ of all the responses, and unique, with $5.4 \%$. The concepts of design and the arts also made the top- 12 list, with the former in the third position (4.8\%) and the latter in the eighth (3.4\%).

Table 1 . Top 12 attributes of creativity, as reported by the Macau sample

\begin{tabular}{llll}
\hline \multicolumn{1}{c}{ Category } & & Frequency & \% of all responses \\
\hline 1. New & 21 & 5.9 \\
2. Unique & 19 & 5.4 \\
3. Design & 17 & 4.8 \\
4. Different & 15 & 4.2 \\
5. Inspiration & 15 & 4.2 \\
6. Interesting & 14 & 3.9 \\
7. Innovation & 13 & 3.7 \\
8. Arts & 12 & 3.4 \\
9. Special & 12 & 3.4 \\
10. Novel & 11 & 3.1 \\
11. Fun & 9 & 2.5 \\
12. Surprise & 9 & 2.5 \\
Total & 167 & 47.5 \\
\hline
\end{tabular}

Table 2. Top 12 attributes of creativity, by respondents' genders

\begin{tabular}{|c|c|c|c|c|}
\hline Category & Male (n) & Female (n) & Chi-square & $p$ \\
\hline 1. New & 6 & 15 & 3.86 & .049 \\
\hline 2. Unique & 8 & 11 & 0.47 & .491 \\
\hline 3. Design & 8 & 9 & 0.05 & .808 \\
\hline 4. Different & 6 & 9 & 0.60 & .438 \\
\hline 5. Inspiration & 9 & 6 & 0.60 & .438 \\
\hline 6. Interesting & 2 & 12 & 7.14 & .007 \\
\hline 7. Innovation & 7 & 6 & 0.07 & .781 \\
\hline 8. Arts & 4 & 8 & 1.33 & .248 \\
\hline 9. Special & 6 & 6 & 0 & 0 \\
\hline 10. Novel & 6 & 5 & 0.09 & .763 \\
\hline 11. Fun & 4 & 5 & 0.11 & .738 \\
\hline 12. Surprise & 3 & 6 & 1 & .317 \\
\hline
\end{tabular}

In order to understand possible gender influences on our participants' implicit theories of 
creativity, chi-square tests were conducted to compare the gender differences in each of the top 12 categories listed above. Significant differences were found in only two categories: new $\left(\chi^{2}=3.86, p=.049\right)$ and interesting $\left(\chi^{2}=7.14, p=.007\right)$. For the concept of new, female students $(n=15)$ had a higher response rate than males did $(n=6)$, and for the concept interesting, females $(\mathrm{n}=12)$ had a much higher response rate than males did $(\mathrm{n}=2)$.

\section{Discussion}

When our sample of art and design college students in Macau were asked to define creativity in their own words, the majority of the most popular responses seemed to reflect the creativity literature, with new, unique, surprise, and interesting (see Runco \& Jaeger, 2012; Simonton, 2012) according for more than one-sixth (17.7\%) of all responses were received. To the extent that the additional top-12 terms novel, innovation, and different can be taken as synonymous or nearly synonymous with new and/or surprise, this rises to $28.7 \%$. Another widely accepted attribute of creativity, at least among explicit theories, is its effectiveness (Hennessey \& Amabile, 2010). Although this concept was not reflected in the top 12 categories of the responses we received, a number of our participants related creativity to money, or mentioned that creativity should be accepted by others. This latter finding appears to be inconsistent with Ramos and Puccio's (2014) study, in that they found the absence of these concepts. It is possible that when our group of art and design students thought about creativity, many presumed that its cardinal purpose was the invention of creative products with strong functionality.

Indeed, the arts and design were important components of our sample's implicit theories of creativity, while the category of scientific creativity seemed to be wholly absent from their responses. The absence of this concept was also noted in other studies (e.g., Paletz \& Peng, 2008), suggesting that educational background may play an important role in shaping an individual's implicit theory of creativity (Tang, Baer, \& Kaufman, 2015).

\section{Limitations}

Several caveats should be considered in the interpretation of the current study's results. Our list of codes was generated using only Chinese undergraduates from an art and design program, and the participants would have been immediately aware (from the single survey item) that the study was focused on creativity. Both of these factors could have generated bias in the descriptions of creativity that were collected. As such, future research should collect such descriptions from a more culturally diverse group of participants in multiple fields, and perhaps include dummy questions to make it less obvious what the main focus of the enquiry is. Nevertheless, the current study has provided some interesting insight into implicit theories of creativity in the Chinese context.

\section{Conclusion}

Our Chinese participants' implicit theories of creativity appear to have been broadly consistent with the ideas of creativity scholars. Specifically, our sample defined creativity from a product perspective, including unique, new, interesting, and surprise as key attributes. In addition, among these four attributes, female students were significantly more concerned 
that creativity should have new and interesting components than their male counterparts did. The main reason for the existing of gender difference is unknown. Our sample is neither experts nor ordinary people, and for the best, they could be treated as quasi-experts (Tsai, 2016). As such, our findings suggest that their implicit theories of creativity were similar to those of the creativity scholars, which also lends support to Tsai's findings that undergraduates from the art and design program can be viewed as valid experts to judge creative products.

\section{References}

Hennessey, B. A., \& Amabile, T. M. (2010). Creativity. Annual Review of Psychology, 61(1), 569-598. http://dx.doi.org/10.1146/annurev.psych.093008.100416

HyperRESEARCH (Version 3.5) [Computer software]. (2013). Randolph, MA: Researchware.

Kirton, M. J. (1976). Adaptors and innovators: A description and measure. Journal of Applied Psychology, 61, 622-629. http://dx.doi.org/10.1037/0021-9010.61.5.622

Lan, L., \& Kaufman, J. C. (2012). American and Chinese similarities and differences in defining and valuing creative products. The Journal of Creative Behavior, 46(4), 285-306. http://dx.doi.org/10.1002/jocb.19

Misra, G., Srivastava, A. K., \& Misra, I. (2006). Culture and facets of creativity. In James C. Kaufman \& Robert J. Sternberg (Eds.), The international handbook of creativity (pp. 421-455). New York, NY: Cambridge University Press. http://dx.doi.org/10.1017/CBO9780511818240.015

Paletz, S. B. F., \& Peng, K. (2008). Implicit theories of creativity across cultures: Novelty and appropriateness in two product domains. Journal of Cross-Cultural Psychology, 39(3), 286-302. http://dx.doi.org/10.1177/0022022108315112

Paletz, S. B. F., Peng, K., \& Li, S. (2011). In the world or in the head: External and internal implicit theories of creativity. Creativity Research Journal, 23(2), 83-98. http://dx.doi.org/10.1080/10400419.2011.571181

Ramos, S. J., \& Puccio, G. J. (2014). Cross-cultural studies of implicit theories of creativity: A comparative analysis between the United States and the main ethnic groups in Singapore.

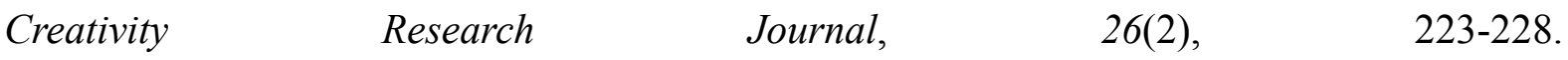
http://dx.doi.org/10.1080/10400419.2014.901094

Runco, M. A., \& Jaeger, G. J. (2012). The standard definition of creativity. Creativity Research Journal, 24(1), 92-96. http://dx.doi.org/10.1080/10400419.2012.650092

Runco, M. A., \& Johnson, D. J. (2002). Parents' and teachers' implicit theories of children's creativity: A cross-cultural perspective. Creativity Research Journal, 14(3/4), 427-438. http://dx.doi.org/10.1207/S15326934CRJ1434_12

Simonton, D. K. (2012). Taking the U.S. patent office criteria seriously: A quantitative 


\section{Macrothink}

Journal of Asian Development

ISSN 2377-9594 2016, Vol. 2, No. 1

three-criterion creativity definition and its implications. Creativity Research Journal, 24(2-3), 97-106. http://dx.doi.org/10.1080/10400419.2012.676974

Sternberg, R. J. (1985). Implicit theories of intelligence, creativity, and wisdom. Journal of Personality and Social

http://dx.doi.org/10.1037/0022-3514.49.3.607

Psychology,

49(3),

607-627.

Tang, C., Baer, J., \& Kaufman, J. C. (2015). Implicit theories of creativity in computer science in the United States and China. The Journal of Creative Behavior, 49(2), 137-156. http://dx.doi.org/10.1002/jocb.61

Tsai, K. C. (2016). Quasi-experts' assessments of creative products: An evaluation using a sample of design students. British Journal of Education, Society \& Behavioural Science, 12(3), 1-7. http://dx.doi.org/10.9734/BJESBS/2016/21057

\section{Copyright Disclaimer}

Copyright reserved by the authors.

This article is an open-access article distributed under the terms and conditions of the Creative Commons Attribution license (http://creativecommons.org/licenses/by/3.0/). 